\title{
SARS-CoV-2 Aerosol and Surface Contamination in Health Care Settings: The Moscow Pilot Study
}

Aerosol and Air Quality Research

Special Issue:

Special Issue on COVID-19 Aerosol Drivers, Impacts and Mitigation (XII)

\author{
Andrei A. Pochtovyi ${ }^{1,2^{*}}$, Valeria V. Bacalin ${ }^{3}$, Nadezhda A. Kuznetsova ${ }^{1}$, \\ Maria A. Nikiforova ${ }^{1}$, Elena V. Shidlovskaya ${ }^{1}$, Bakhtiyar I. Verdiev ${ }^{1}$, \\ Ekaterina N. Milashenko ${ }^{1}$, Alexey M. Shchetinin ${ }^{1}$, Ol'ga A. Burgasova ${ }^{3}$, \\ Ludmila V. Kolobukhina ${ }^{1}$, Svetlana V. Smetanina ${ }^{4}$, Artem P. Tkachuk ${ }^{1}$, \\ Vladimir A. Gushchin ${ }^{1,2^{*}}$, Alexander L. Gintsburg ${ }^{1,5}$ \\ ${ }^{1}$ National Research Center for Epidemiology and Microbiology named after Honorary \\ Academician N.F. Gamaleya of the Ministry of Health of the Russian Federation, 123098 \\ Moscow, Russia \\ ${ }^{2}$ Lomonosov Moscow State University, 119991 Moscow, Russia \\ ${ }^{3}$ Peoples' Friendship University of Russia (RUDN University), 117198 Moscow, Russia \\ ${ }^{4}$ Moscow Healthcare Department, 127006 Moscow, Russia \\ ${ }^{5}$ Infectiology Department, I. M. Sechenov First Moscow State Medical University, 119146 \\ Moscow, Russia
}

\section{ABSTRACT}

The ongoing worldwide COVID-19 pandemic caused by SARS-CoV-2 has had serious impacts on not only the health care system but also all sectors of the economy. Thanks to the adoption of various epidemiological measures, a significant reduction in new cases of infection has been achieved. However, there are still "hotspots", such as healthcare settings focused on treating patients with COVID-19, which are characterized by the risk of nosocomial transmission among health care workers, patients, and visitors. The proper monitoring and timely detection of pathogens in a hospital environment will help prevent further spread of coronavirus infection. In this study, we collected samples from the air and surface swabs at the First Moscow Infectious Diseases Hospital to study the spread of the SARS-CoV-2 in various hospital locations. More than 130 aerosol and surface samples were collected and analysed by RT-PCR. We detected viral contamination of the air in the intensive care unit (ICU) but not in the respiratory infection department where less severe patients are treated. The concentration of SARS-CoV-2 RNA was low, consisting of less than one copy per litre of air. The contact surfaces in both departments were contaminated with SARS-CoV-2. Considering the possible transmission of SARS-CoV- 2 through fomites, these results indicate the need to strictly follow personal hygiene rules as well as wear personal protective equipment to prevent disease spread.

Andrei A. Pochtovyi
a.pochtovyy@gmail.com
Vladimir A. Gushchin
wowaniada@gmail.com

Publisher:

Keywords: COVID-19, SARS-CoV-2, Aerosol, Healthcare, Disease control

\section{INTRODUCTION}

The emergence and rapid spread of novel SARS-CoV-2 has caused a new COVID-19 pandemic (Li et al., 2020). It is necessary to understand the mechanisms and pathways of SARS-CoV-2 transmission to effectively control its spread. Moreover, it is necessary to understand the factors contributing to preservation in the environment before a susceptible organism invades. According to the current understanding, the main mechanisms of SARS-CoV-2 transmission include aerogenic and contact transmission (Ghinai et al., 2020; Pastorino et al., 2020; Peng et al., 2020; Richard et al., 2020). Thus, aerosols, air droplets and dust as well as surfaces can all be contaminated with SARS-CoV-2. According to the literature, air droplets seems to be the 
predominant source of infection, although the probability of transmission by aerosols and airborne dust seems to be high, potentially resulting in superspreading events (Allen and Marr, 2020; Ge et al., 2020; Sommerstein et al., 2020; Stadnytskyi et al., 2020). A number of studies have demonstrated the ability of SARS-CoV-2 to remain viable on aerosolized air particles for up to 3-16 hours (Fears et al., 2020; van Doremalen et al., 2020) and on various surfaces for up to several days (van Doremalen et al., 2020). The ability of viral particles to settle while maintaining their viability on solid surfaces indicates the possibility of transmission through fomites (Chia et al., 2020; Guo et al., 2020; Wu et al., 2020; van Doremalen et al., 2020).

Despite the achieved reduction in the number of new cases of SARS-CoV- 2 infection as a result of adopted anti-epidemic measures, there are still "hot spots" in the form of health care institutions, where medical personnel come into close contact with COVID-19 patients. Previous experience suggests a high risk of transmission of coronaviruses in hospitals (Bin et al., 2015; Chowell et al., 2015). For SARS-CoV-2, the risk of transmission in hospitals is high, as evidenced by outbreaks in various medical institutions around the world (Gao et al., 2020; Heinzerling et al., 2020; Komissarov et al., 2020; Sommerstein et al., 2020).

In hospital settings, infection control is essential to improve effective measures to protect health care workers and prevent the spread of COVID-19. This circumstance requires the development of highly effective methods for indicating pathogens of respiratory infections, including SARS-CoV-2. Early proposed serological and molecular genetic (PCR) studies of biomaterials from patients and medical workers made it possible to detect asymptomatic as well as clinically expressed forms of the disease (Arons et al., 2020; Goldberg et al., 2020; Kucharski and Nilles, 2020). However, despite the importance of these methods, they do not allow us to study the contamination sources.

To monitor and detect pathogens of respiratory infections, including SARS-CoV-2, in a timely manner in hospital setting, it is possible to use an integrated approach, including the use of highly efficient aerosol samplers in addition to swab samples from various surfaces, to indicate pathogens of infectious diseases. This paper presents the results of the Moscow pilot study of the presence of SARS-CoV-2 in aerosol samples and surface swabs from different locations in the respiratory infection department and intensive care units of the First Infectious Diseases Hospital in Moscow (Russia).

\section{METHODS}

\subsection{Sample Collection Sites}

Samples were collected in the wards and rooms of patients with a positive PCR result and a confirmed diagnosis of COVID-19 in the respiratory infection department (RI) and in the intensive care unit (ICU) of the First Infectious Diseases Hospital of Moscow (Russia).

\subsection{Air Sampling}

SASS 4000/2300 (Research International Inc., USA) with a virtual impactor and Cyclone-Bio (Akmalov et al., 2018) aerosol samplers were used for highly efficient aerosol sampling. The aerosol samplers used in this work are based on similar operating principles. A sterile PBS solution was used as a liquid that acts as a solvent for solid particles contained in the aerosol. The sterile PBS solution was aseptically poured into aerosol samplers immediately prior to sampling and was also used for flushing the sampler between different collection points. Both devices were set for an air flow rate of $4000 \mathrm{~L} \mathrm{~min}^{-1}$, with a collection time of 20 minutes. To comply with the relevant noise exposure standards, collection using the complex SASS 4000/2300 and/or the Cyclone-Bio sampler was carried out only in the lobbies of the departments. Aerosol collection was carried out using a SASS 2300 sampler with an air flow rate of $325 \mathrm{~L} \mathrm{~min}^{-1}$ and a collection duration of 5 minutes in the wards and rooms of hospitalized patients. The instrument was flushed for 8 minutes by default before moving to a new collection point. Before changing the compartment, all samplers were disinfected by washing and wiping the surfaces of the samplers and impactors, as well as soaking the connecting hoses in a $3 \%$ solution of sodium hypochlorite. Aerosol collection points in general wards and the intensive care unit are shown in Fig. 1. Our samplers in the abovementioned wards were located at a height of approximately $1.5 \mathrm{~m}$ from the floor and 2-3 $\mathrm{m}$ from patients' beds. 
A
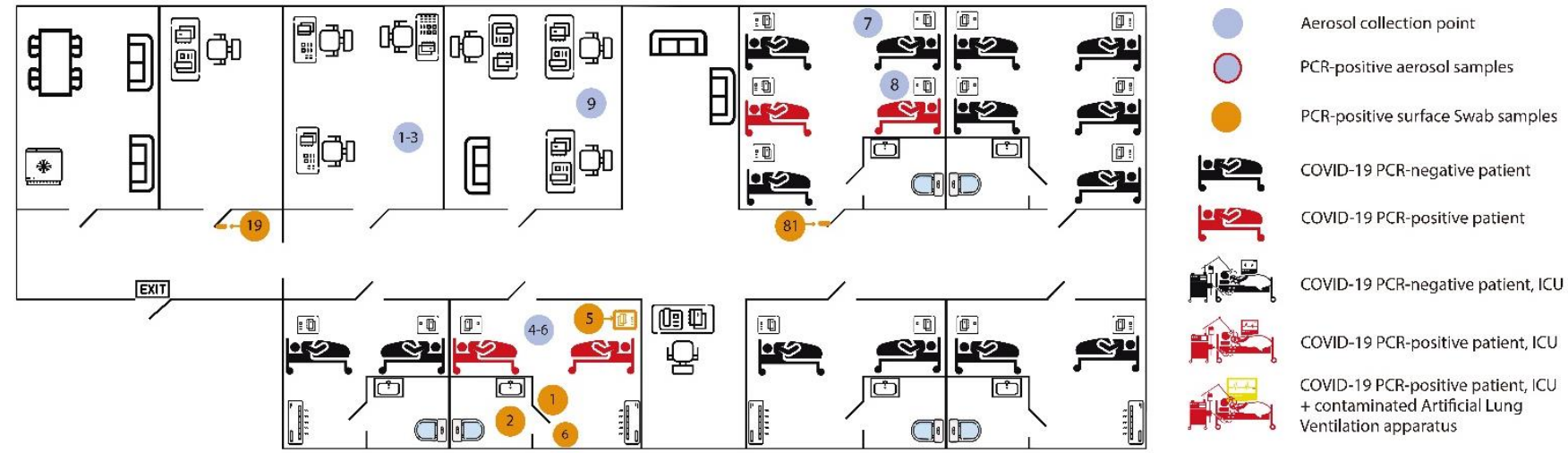

B

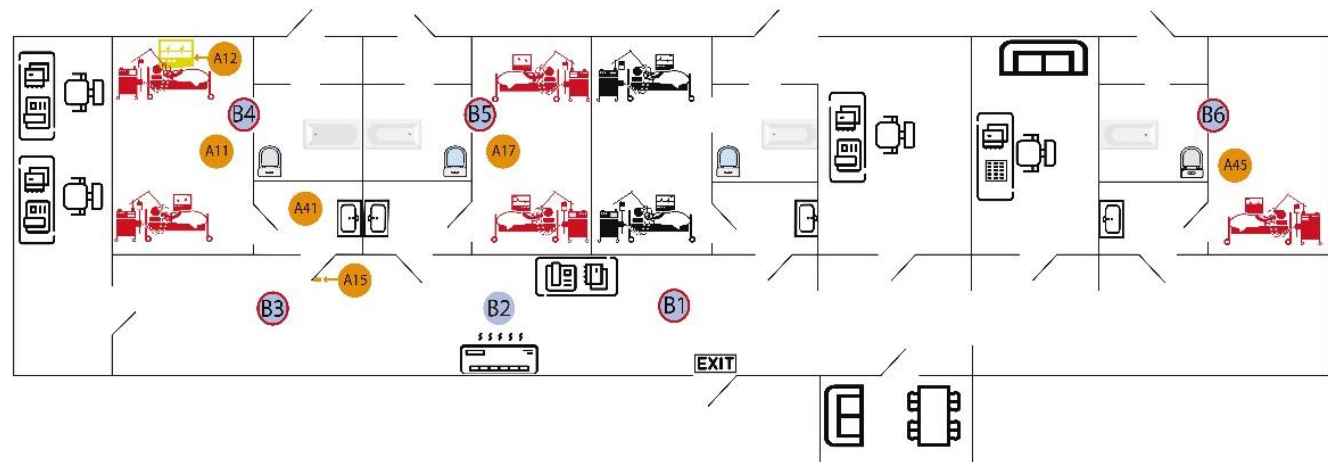

Fig. 1. Schematic representation of the (a) respiratory infections department and (b) intensive care unit. The blue circles indicate the installation points of the aerosol samplers (the sample number corresponds to the sample number in Table S1). The blue circles with red edging indicate SARS-CoV-2 positive aerosol sample. Orange numbered circles indicate SARS-CoV-2 positive swabs from surfaces (the sample number corresponds to the sample number in Table S2). In Fig. 1(a) beds indicate the presence of a patient, patients with COVID-19 are indicated in red color. In Fig. 1(b), patients with COVID-19 are indicated red color, and patients with a different diagnosis are indicated black color. These rooms belong to the "red zone".

The number of viral genome equivalents present in the collection sample was estimated by quantitative RT-PCR. To determine the copy number of SARS-CoV-2 RNA in the air, the following Eq. (1) was used:

copies $\mathrm{m}^{-3}=\frac{G E \mathrm{~mL}^{-1} \times V_{\text {sample }}}{V_{m^{3}} \times \text { Efficiency Air Sampler }}$

where $\mathrm{GE} \mathrm{mL}^{-1}$ is the amount of genome equivalent in $1 \mathrm{~mL}$ (Table 3), $\mathrm{V}_{\text {sample }}$ is the volume of the collected sample $(4.5 \mathrm{~mL}), \mathrm{V}_{\mathrm{m}}$ is the volume of collected air (for SASS 4000/2300, the volume is $80 \mathrm{~m}^{3}$, for SASS 2300 volume is $1.625 \mathrm{~m}^{3}$ ), and Efficiency Air Sampler is the for SASS 4000/2300: 0.20 ; SASS 2300: 0.60 .

\subsection{Surface Sampling}

Surface samples were collected using a sterile viscose "Tampon-probe" swab (MiniMed, Russia). Before collection, the swab was pre-moistened in sterile PBS solution, and sampled were collected from a surface area of $25 \mathrm{~cm}^{2}$. The volume of each sample with washout from the surface was $0.5 \mathrm{ml}$. Our attention was focused on surfaces where direct contact between patients and medical personnel potentially occurred (Table 1 ).

\subsection{Sample Transport, Processing and Detection of SARS-CoV-2 Using RT-PCR}

All collected samples were immediately placed in a thermal bag at $+4^{\circ} \mathrm{C}$ and transported within 1-2 hours after collection to a BSL-3 laboratory. The obtained samples were aliquoted and 
Table 1. Description of the location and points of collection of washes from surfaces.

\begin{tabular}{lc}
\hline Area & Point \\
\hline Wards/rooms & $\begin{array}{c}\text { Floor, bedside table, window handle, doorknob, light switch, headboard, phone } \\
\text { screen, bed sheet, call button, inhalation mask, bedside rails, electronics, } \\
\text { ventilator tube } \\
\text { Floor, doorknob } \\
\text { Anteroom }\end{array}$ \\
$\begin{array}{l}\text { Floor, door handle, toilet (seat), faucet, sink } \\
\text { Lobby }\end{array}$ & $\begin{array}{c}\text { Floor, reception telephone receiver, paperwork table, thermometer container, } \\
\text { doctors' shoes, sofa, reception hallway parapet, food service table, dirty dish }\end{array}$ \\
& table, dirty linen trolley, food refrigerator \\
Nurse's room (2-4 people), staff room & Floor, mirror, table, clean linen closet, food refrigerator \\
(3-4), cafeteria (varies from 1-6) & Inhaler, refrigerator door, PPE suit (chest part), wheelchair handle for patients with \\
Other & COVID-19, inhalation mask (outer part), water bottle (neck), air conditioner, mug, \\
& personal towel, personal item (bathrobe), personal thermometer, bed sheet \\
\hline
\end{tabular}

deposited for preservation at $-80^{\circ} \mathrm{C}$. We have used the commercial reagent kit for the extraction and qualitative determination of SARS-CoV-2 RNA by the RT-PCR technique "SARS-CoV-2 FRT» manufactured by N.F. Gamaleya National Research Center, Russia, catalog number is EA-96-01. This kit detects nsp1 gene located closer to the $5^{\prime}$-end of the SARS-CoV-2 genome. The concentrations of viral RNA in air and swab samples were determined using in-house plasmid controls with known copy numbers.

\section{RESULTS AND DISCUSSION}

\subsection{SARS-CoV-2 RNA Air and Surface Contamination Assessment}

The onward spread of the novel coronavirus infection continues to be a cause of concern. Currently, the main routes of SARS-CoV-2 transmission are considered to be aerosol droplets and direct contact with contaminated surfaces (WHO, 2020). Given these modes of transmission, as well as the possibility of transmission of the virus from an asymptomatic carrier, it is necessary to carry out studies for the presence of SARS-CoV-2 nucleic acids in aerosols and surfaces, which will allow assessing biosafety in crowded places, as well as confined spaces, such as hospitals, to determine the most likely infected sites. Determination of the hot spots of contamination will allow taking appropriate measures to prevent further spread in medical institutions, primarily among health workers, who account for a third of cases of the disease (Wee et al., 2020).

This study was conducted from June 15 to June 25 in the respiratory infection department (RI) and intensive care unit (ICU) at the First Infectious Diseases Hospital in Moscow (Russia). The collection of samples was carried out in different wards and rooms of patients with a confirmed diagnosis of COVID-19 and a positive PCR result. During this period, over 600 new cases were reported in Moscow daily. This period can be characterized as a period of decrease in the incidence rate since at the peak, the number of new cases was more than 6,700 per day.

A total of 131 samples were collected for this study (Table 2): 15 aerosol samples (9 samples from respiratory infections department and 6 samples - from ICU) and 116 swabs were collected from various surfaces ( 82 swabs were collected from surfaces in the respiratory infections department and 34 swabs - in ICU). Fig. 1 and Table S1, Table S2 provide additional information on the location and method of sample collection.

PCR analysis of aerosol samples identified SARS-CoV-2 RNA in only the intensive care unit. Of the six sampling points, five were positive. It is worth noting that the negative sample was the second sample collected and was located directly under a supply ventilation unit. Importantly, SARS-CoV-2 RNA was detected in the hallway that was considered a clean zone (Fig. 1(b)). The total concentration of SARS-CoV-2 ranged from 28.13 to 140.63 copies of RNA per $1 \mathrm{~m}^{3}$ of air sample in the hallway and 512.82 copies of RNA per $1 \mathrm{~m}^{3}$ of air sample in rooms of COVID-19 patients (Table 3). In the respiratory infections department, the presence of SARS-CoV-2 in aerosols was not detected despite the use of high-performance samplers and the collection of more air. 
Table 2. Total number of samples and number of positive samples by location.

\begin{tabular}{lll}
\hline Area & Aerosol samples/Positive samples/Positive & $\begin{array}{l}\text { Surface/Positive samples/Positive } \\
\text { sample, } \%\end{array}$ \\
\hline Respiratory infection department & $9 / 0 / 0 \%$ & $82 / 6 / 7.32 \%$ \\
Intensive care unit & $6 / 5 / 83.3 \%$ & $34 / 6 / 17.65 \%$ \\
Total & $15 / 5 / 31.25 \%$ & $116 / 12 / 10.3 \%$ \\
\hline
\end{tabular}

Table 3. Calculation of copies of SARS-CoV-2 in aerosols.

\begin{tabular}{lllllll}
\hline Sample & GE mL $\mathrm{mL}^{-1}$ & V sample, $\mathrm{mL}$ & Duration of collection, $\mathrm{min}$ & V air, $\mathrm{m}^{3}$ & Efficiency Air Sampler & ${\text { Copies } \mathrm{m}^{-3}}$ \\
\hline B1 & 100 & 4.5 & 20 & 80.000 & 0.20 & 28.13 \\
B2 & 0 & 4.5 & 20 & 80.000 & 0.20 & 0 \\
B3 & 500 & 4.5 & 20 & 80.000 & 0.20 & 140.63 \\
B4 & 100 & 5 & 5 & 1.625 & 0.60 & 512.82 \\
B5 & 100 & 5 & 5 & 1.625 & 0.60 & 512.82 \\
B6 & 100 & 5 & 5 & 1.625 & 0.60 & 512.82 \\
\hline
\end{tabular}

Several studies have similarly noted a higher contamination rate in the intensive care units compared to other departments aimed at combating COVID-19 (Hirota, 2020; Ye et al., 2020). This can be explained by various factors. Firstly, the efficiency of the active ventilation system in the intensive care unit can be insufficient although it meets the recommended regulatory criteria of at least 2-6 total air changes per hour (ACH) (CDC, 2003; Sanitary Norms and Regulations of the Russian Federation, 2010). Secondly, significant contamination of SARS-CoV-2 RNA may be associated with cleaning regimes in the hospital, as well as with the spread by medical personnel themselves. In addition, Siegel et al. (2007) reported that ventilators can emit respiratory aerosols. Therefore, we observed large contamination with the SARS-CoV-2 virus in ventilated boxes in the intensive care unit.

It is worth noting that the $\mathrm{Ct}$ (cycle threshold) values were close to the detection limit, indicating a low viral load. The reason for such a low amount of the virus may be related to the hospitalization of patients in the late stages of the disease and their prolonged stay in the intensive care unit. Other research groups have come to the same conclusion (Nissen et al., 2020).

In addition to aerosols, SARS-CoV-2 RNA was detected on the surfaces of handles and floors and the screen of the Artificial Lung Ventilation apparatus. In all, 6 positive samples from surfaces were detected in the intensive care unit: 4 positive samples were taken from the floor, and one positive sample each was obtained from a door handle and the screen of an Artificial Lung Ventilation apparatus (Fig. 1).

Six positive swabs were detected in the respiratory infections department: 2 positive samples from the floor, 2 - from door handles, one - from the surface of a bedside table, and one from a window handle in the ward (Fig. 1). A total of 12 positive samples were detected during this study from surfaces in various locations (Fig. 2). The results obtained were consistent with previously obtained data from studies conducted in various medical institutions (Chia et al., 2020; Guo et al., 2020; Ong et al., 2020). The result may indicate that the accepted disinfection frequency does not allow complete decontamination. It is worth noting that the detection of SARS-CoV-2 RNA in environmental samples is not the proof of the virus viability and it is extremely difficult to assess the potential risks for infection.

Besides, it was difficult to assess the potential risk of infection by aerosols in the intensive care unit due to a lack of data on the viability of the virus in the collected samples, as well as a lack of information on the minimum infectious dose of SARS-CoV-2 in humans. The infectious dose assessment in humans requires intranasal administration of the virus via drops or aerosols (Karimzadeh et al., 2020). To our knowledge, no given values for SARS-CoV-2 human infectious dose were reported yet. In several animal studies, the infectious dose was at least 500 plaqueforming unit (PFU) administered intranasally to hamsters (Ryan et al., 2020) and 630 PFU for aerosol transmission in mice (Karimzadeh et al., 2020). This amount of the virus was sufficient to cause various disease symptoms in laboratory animals, such as pneumonia. 


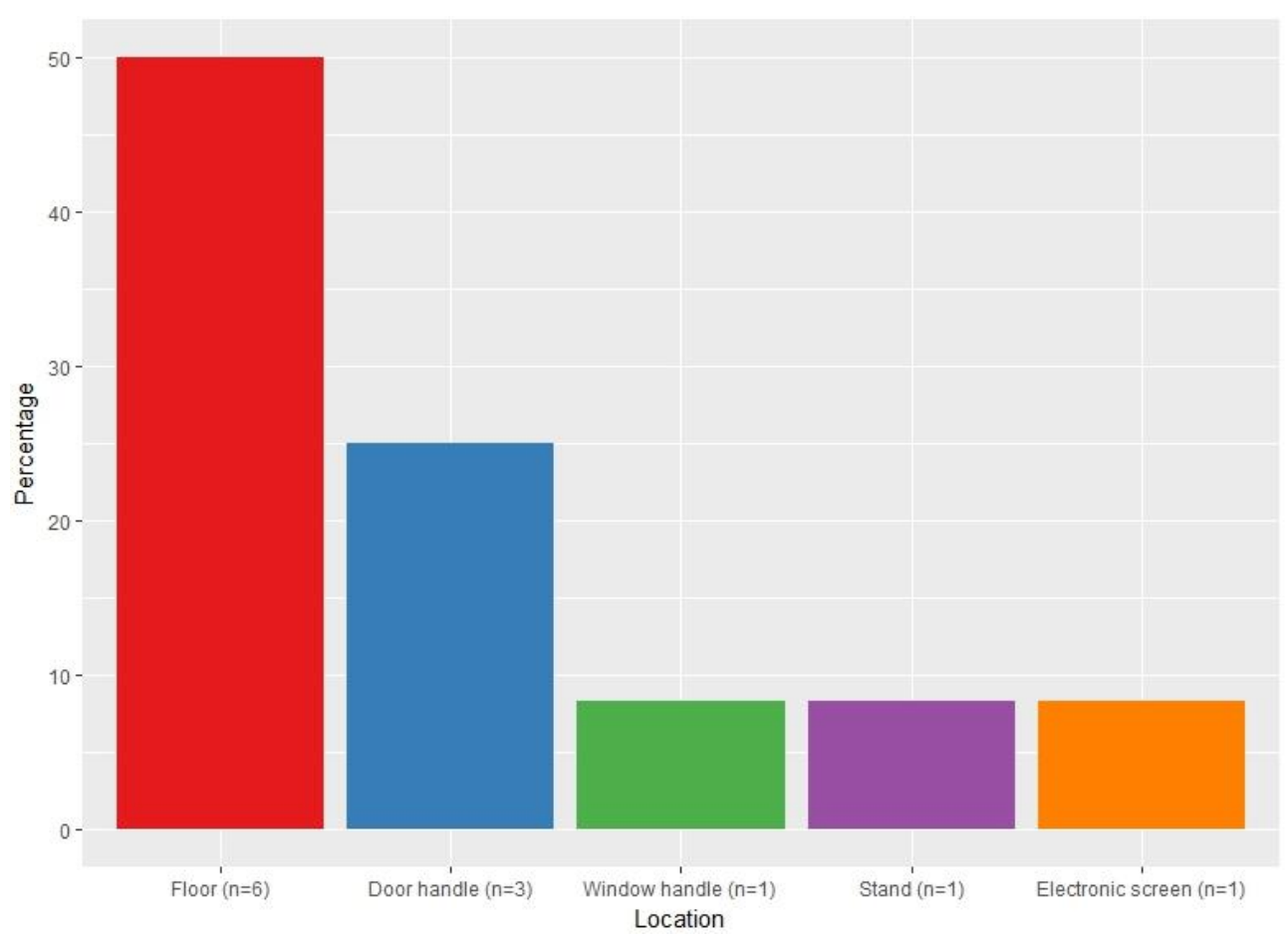

Fig. 2. Distribution of positive washouts by surface.

At the same time, the infectious dose for SARS-CoV-1 was defined as 280 viral particles infectious dose (ID50) (Watanabe et al., 2010). These values are similar to infectious dose for seasonal human coronaviruses and some animal coronaviruses belonging to the same genetic group as SARS-CoV-1 (Watanabe et al., 2010; Schröder, 2020). It can be assumed that the minimum infectious dose is more than 100 SARS-CoV-2 viral particles (Karimzadeh et al., 2020). The Lednicky study demonstrated the ability to detect the SARS-CoV-2 virus at a distance of up to 4.8 metres from a patient with COVID-19. The SARS-CoV-2 concentration measured with qPCR ranged from 16 to $94 \mathrm{GE}$ in 1 litre of air, while the number of viable virus particles ranged from 6 to 74 TCID50/L of air (Lednicky et al., 2020). Based on the results of previous studies on the infectiousness of SARS-CoV-2 and SARS-CoV-1 (Karimzadeh et al., 2020; Watanabe et al., 2010), it can be assumed that there is a potentially dangerous amount of virus in the intensive care unit. We used information on the amount of live virus in 1 liter of air, took into account that on average an adult inhales 7-10 liters of air per minute, and recalculated the amount of virus in the aerosol samples we collected. Our calculations showed that a 5 to 50 minutes exposition of a person without protective equipment to the contaminated aerosols in the hospital ICU corresponds to the acquisition of SARS-CoV-2 infectious dose. It is worth noting that further research on the infectiousness of SARS-CoV-2 will help clarify these risks.

\subsection{Risks of SARS-CoV-2 RNA Contamination around the COVID-19 Patient}

For an in-depth study of the possibility of SARS-CoV-2 contamination of fomites near a patient with COVID-19, we examined aerosols in the immediate proximity (within a radius of $0.5 \mathrm{~m}$ ) of a patient for the presence of SARS-CoV-2 RNA. Additionally, swabs were taken from the surfaces of objects that were in direct contact with the patient; in particular, swabs were taken from the surface of the patient's bedside table, back of the bed, medical call button, a blanket and a towel, an inhalation mask (from the outside and inside), the mug, the patient's personal phone, the neck of a bottle of water and the skin of the patient's hand. We received the patient's written consent to collect the samples. It is known from the anamnesis that the patient felt the first symptoms of the disease on June 08, and a week later (June 15), he was admitted to the Department of Respiratory Infections with the following symptoms: weakness, headache, and fever reaching $37.4^{\circ} \mathrm{C}$. PCR analysis of the nasopharyngeal swab at the time of hospitalization confirmed the presence of SARS-CoV-2 RNA, with a cycle threshold of 25.4 (approximately $5 \times 10^{6} \mathrm{GE} \mathrm{mL} \mathrm{m}^{-1}$ ). The 
patient was prescribed antiviral and antibacterial therapies. Aerosol samples and surface swab were collected on the third day of hospitalization in the department and 9 hours after the morning cleaning of the premises, which resulted in a negative result (Table S3), while the result of the PCR analysis of the nasopharyngeal swab remained positive, with a cycle threshold of 33 (approximately $10^{4} \mathrm{GE} \mathrm{mL}^{-1}$ ). As previously reported (Chia et al., 2020) environmental air and surface contamination by a COVID-19 patient drops significantly after one week of the disease, which clearly corresponds with our results, since no contamination near the patient was detected.

One of the main limitations of our study is the lack of data on the infectivity of SARS-CoV- 2 in the collected samples. This study showed that it is impossible to exclude the circulation of a potentially viable virus in various departments of the First Infectious Diseases Hospital. Further research is needed to determine the infectious potential of the most contaminated locations and to develop more effective treatment regimens and determine proper concentrations of disinfectants to reduce the risk of infection in staff and patients in a hospital setting.

\section{CONCLUSIONS}

Infection control is essential to provide effective measures for protection of health care staff and for prevention of the infectious disease spread including COVID-19. An integrated approach, including the use of highly efficient aerosol samplers as well as swab samples collection from various surfaces, can help to monitor SARS-CoV-2 RNA contamination.

Here we report the successful use of such an approach for detection of SARS-CoV-2 RNA in two different departments of Infectious Diseases Hospital. The presence of SARS-CoV-2 RNA in aerosols was detected only in the intensive care unit. Its concentration reached max value of 512.82 copies per $1 \mathrm{~m}^{3}$ of air. At the same time, we obtained positive results in the samples collected from surfaces with a high level of contact in both departments of the Infectious Diseases Hospital. In particular, the floor, door and window handles, and screen of the ALV apparatus were contaminated. The results may indicate that the applicable disinfection frequency does not allow to achieve a complete decontamination of the premises and emphasizes the importance of safety regulations compliance. These results also demonstrate the potential use of this approach for monitoring of crowded places such as subways, airports, transport hubs, etc.

\section{ACKNOWLEDGMENTS}

This work was supported by the Ministry of Health of the Russian Federation and carried out in the frame of State assignment 056-00034-20-00.

\section{DISCLAIMER}

The authors declare no conflicts of interest. The funders had no role in the design of this study; in the collection, analysis, or interpretation of data; in the writing of the manuscript; or in the decision to publish the results.

\section{SUPPLEMENTARY MATERIAL}

Supplementary data associated with this article can be found in the online version at https://doi.org/10.4209/aaqr.200604

\section{REFERENCES}

Akmalov, A.E., Kotkovskii, G.E., Stolyarov, S.V., Verdiev, B.I., Ovchinnikov, R.S., Pochtovyy, A.A., Tkachuk, A.P., Chistyakov, A.A. (2018). High-performance aerosol sampler with liquid phase recirculation and pre-concentration of particles. Bull. RSMU 7, 25-31. https://doi.org/10.2407 5/brsmu.2018.049 
Allen, J.G., Marr, L.C. (2020). Recognizing and controlling airborne transmission of SARS-CoV-2 in indoor environments. Indoor Air. 30, 557-558. https://doi.org/10.1111/ina.12697

Arons, M.M., Hatfield, K.M., Reddy, S.C., Kimball, A., James, A., Jacobs, J.R., Taylor, J., Spicer, K., Bardossy, A.C., Oakley, L.P., Tanwar, S., Dyal, J.W., Harney, J., Chisty, Z., Bell, J.M., Methner, M., Paul, P., Carlson, C.M., McLaughlin, H.P., Thornburg, N., ... Jernigan, J.A. (2020). Presymptomatic SARS-CoV-2 infections and transmission in a skilled nursing facility. N. Engl. J. Med. 382, 20812090. https://doi.org/10.1056/NEJMoa2008457

Bin, S.Y., Heo, J.Y., Song, M.S., Lee, J., Kim, E.H., Park, S.J., Lee, I.W. (2015). Environmental contamination and viral shedding in MERS patients during MERS-CoV outbreak in South Korea. Clin. Infect. Dis. 62, 755-760. https://doi.org/10.1093/cid/civ1020

CDC and Healthcare Infection Control Practices Advisory Committee (HICPAC) (2003). Guidelines for environmental infection control in health-care facilities. http://www.cdc.gov/hicpac/pdf/g uidelines/eic_in_hcf_03.pdf (accessed: 3 January 2020).

Chia, P.Y., Coleman, K.K., Tan, Y.K., Ong, S.W.X., Gum, M., Lau, S.K., Son, T.T. (2020). Detection of air and surface contamination by SARS-CoV-2 in hospital rooms of infected patients. Nat. Commun. 11, 1-7. https://doi.org/10.1038/s41467-020-16670-2

Chowell, G., Abdirizak, F., Lee, S., Lee, J., Jung, E., Nishiura, H., Viboud, C. (2015). Transmission characteristics of MERS and SARS in the healthcare setting: A comparative study. BMC Med. 13, 1-12. https://doi.org/10.1186/s12916-015-0450-0

Fears, A.C., Klimstra, W.B., Duprex, P., Hartman, A., Weaver, S.C., Plante, K.S., Nalca, A. (2020). Persistence of severe acute respiratory syndrome coronavirus 2 in aerosol suspensions. Emerging Infect. Dis. 26, 2168. https://doi.org/10.3201/eid2609.201806

Gao, S., Yuan, Y., Xiong, Y., Zhang, Y., Deng, L., Chen, T., Wang, X. (2020). Two outbreaks of SARSCoV-2 in department of surgery in a Wuhan hospital. Infect. Prev. Pract. 2, 100065. https://doi.org/10.1016/j.infpip.2020.100065

Ge, Z.Y., Yang, L.M., Xia, J.J., Fu, X.H., Zhang, Y.Z. (2020). Possible aerosol transmission of COVID-19 and special precautions in dentistry. J. Zhejiang Univ. Sci. B. 21, 361-368. https://doi.org/10.1 631/jzus.B2010010

Ghinai, I., McPherson, T.D., Hunter, J.C., Kirking, H.L., Christiansen, D., Joshi, K., Rubin, R., Morales-Estrada, S., Black, S.R., Pacilli, M., Fricchione, M.J., Chugh, R.K., Walblay, K.A., Ahmed, N.S., Stoecker, W.C., Hasan, N.F., Burdsall, D.P., Reese, H.E., Wallace, M., Wang, C., ... Uyeki, T. M. (2020). First known person-to-person transmission of severe acute respiratory syndrome coronavirus 2 (SARS-CoV-2) in the USA. Lancet 395, 1137-1144. https://doi.org/10.1016/S014 0-6736(20)30607-3

Goldberg, S.A., Lennerz, J., Klompas, M., Mark, E., Pierce, V.M., Thompson, R.W. (2020). Presymptomatic transmission of SARS-CoV-2 amongst residents and staff at a skilled nursing facility: Results of real-time PCR and serologic testing. Clin. Infect. Dis. ciaa991. https://doi.org/ 10.1093/cid/ciaa991

Guo, Z.D., Wang, Z.Y., Zhang, S.F., Li, X., Li, L., Li, C., Cui, Y., Fu, R.B., Dong, Y.Z., Chi, X.Y., Zhang, M.Y., Liu, K., Cao, C., Liu, B., Zhang, K., Gao, Y.W., Lu, B., Chen, W. (2020). Aerosol and surface distribution of severe acute respiratory syndrome coronavirus 2 in hospital wards, Wuhan, China, 2020. Emerging Infect. Dis. 26, 1586. https://doi.org/10.3201/eid2607.200885

Heinzerling, A., Stuckey, P.M.J., Scheuer, T., Xu, K., Perkins, K.M., Resseger, H., Magill, S., Verani, J.R., Jain, S., Acosta, M., Epson, E. (2020). Transmission of COVID-19 to Health Care Personnel During Exposures to a Hospitalized Patient - Solano County, California, February 2020. MMWR Morb. Mortal. Wkly Rep. 69, 472-476. https://doi.org/10.15585/mmwr.mm6915e5

Hirota, K. (2020). Air contamination with SARS-CoV-2 in the operating room. J. Anesth. https://doi.org/10.1007/s00540-020-02814-7

Karimzadeh, S., Bhopal, R., Nguyen Tien, H. (2020). Review of infective dose, routes of transmission, and outcome of COVID-19 caused by the SARS-CoV-2 Virus: Comparison with other respiratory viruses. Preprints 2020070613.

Komissarov, A.B., Safina, K.R., Garushyants, S.K., Fadeev, A.V., Sergeeva, M.V., Ivanova, A.A., Danilenko, D.M., Lioznov, D., Shneider, O.V., Shvyrev, N., Spirin, V., Glyzin, D., Shchur, V., Bazykin, G.A. (2020). Genomic epidemiology of the early stages of SARS-CoV-2 outbreak in Russia. medRxiv 2020.07.14.20150979. https://doi.org/10.1101/2020.07.14.20150979

Kucharski, A.J., Nilles, E.J. (2020). Using serological data to understand unobserved SARS-CoV-2 
risk in health-care settings. Lancet Infect. Dis. 3099, 10-11. https://doi.org/10.1016/S14733099(20)30579-X

Lednicky, J.A., Lauzardo, M., Fan, Z.H., Jutla, A., Tilly, T.B., Gangwar, M., Usmani, M., Shankar, S.N., Mohamed, K., Eiguren-Fernandez, A., Stephenson, C.J., Alam, M.M., Elbadry, M.A., Loeb, J.C., Subramaniam, K., Waltzek, T.B., Cherabuddi, K., Morris, J.G., Wu, C.Y. (2020). Viable SARS CoV-2 in the air of a hospital room with COVID-19 patients. Int. J. Infect. Dis. 100, 476-482. https://doi.org/10.1016/j.ijid.2020.09.025

Li, Q., Guan, X., Wu, P., Wang, X., Zhou, L., Tong, Y., Ren, R., Leung, K.S.M., Lau, E.H.Y., Wong, J.Y., Xing, X., Xiang, N., Wu, Y., Li, C., Chen, Q., Li, D., Liu, T., Zhao, J., Liu, M., Tu, W., ... Fang, Z. (2020). Early transmission dynamics in Wuhan, China, of novel coronavirus-infected pneumonia. N. Engl. J. Med. 382, 1199-1207. https://doi.org/10.1056/NEJMoa2001316

Nissen, K., Krambrich, J., Akaberi, D., Hoffman, T., Ling, J., Lundkvist, Å., Svensson, L., Salaneck, E. (2020). Long-distance airborne dispersal of SARS-CoV-2 in COVID-19 wards. Sci. Rep. 10, 19589. https://doi.org/10.1038/s41598-020-76442-2

Ong, S.W.X., Tan, Y.K., Chia, P.Y., Lee, T.H., Ng, O.T., Wong, M.S.Y., Marimuthu, K. (2020). Air, surface environmental, and personal protective equipment contamination by severe acute respiratory syndrome coronavirus 2 (SARS-CoV-2) from a symptomatic patient. JAMA 323, 1610-1612. https://doi.org/10.1001/jama.2020.3227

Pastorino, B., Touret, F., Gilles, M., de Lamballerie, X., Charrel, R.N. (2020). Prolonged infectivity of SARS-CoV-2 in fomites. Emerging Infect. Dis. 26, 2256-2257. https://doi.org/10.3201/eid26 09.201788

Peng, X., Xu, X., Li, Y., Cheng, L., Zhou, X., Ren, B. (2020). Transmission routes of 2019-nCoV and controls in dental practice. Int. J. Oral Sci. 12, 9. https://doi.org/10.1038/s41368-020-0075-9

Richard, M., Kok, A., de Meulder, D., Bestebroer, T.M., Lamers, M.M., Okba, N.M.A., Fentener van Vlissingen, M., Rockx, B., Haagmans, B.L., Koopmans, M.P.G., Fouchier, R.A.M., Herfst, S. (2020). SARS-CoV-2 is transmitted via contact and via the air between ferrets. Nat. Commun. 11, 3496. https://doi.org/10.1038/s41467-020-17367-2

Ryan, K.A., Bewley, K.R., Fotheringham, S.A., Brown, P., Hall, Y., Marriott, A.C., Tree, J.A., Allen, L., Aram, M.J., Brunt, E., Buttigieg, K.R., Cavell, B.E., Carter, D.P., Cobb, R., Coombes, N.S., Godwin, K.J., Gooch, K.E., Gouriet, J., Halkerston, R., Harris, D.J., ... Carroll, M.M (2020). Dosedependent response to infection with SARS-CoV-2 in the ferret model: Evidence of protection to re-challenge. bioRxiv 2020.05.29.123810. https://doi.org/10.1101/2020.05.29.123810

Sanitary and Epidemiological rules and hygienic regulations № 2.1.3.2630-10 (2010). http://www.consultant.ru/document/cons_doc_LAW_104071/ (accessed: 3 January 2020).

Schröder, I. (2020). COVID-19: A risk assessment perspective. ACS Chem. Health Saf. 27, 160-169. https://doi.org/10.1021/acs.chas.0c00035

Siegel, J.D., Rhinehart, E., Jackson, M., Chiarello, L. (2007). 2007 guideline for isolation precautions: Preventing transmission of infectious agents in health care settings. Am. J. Infect. Control 35, S65-S164. https://doi.org/10.1016/j.ajic.2007.10.007

Sommerstein, R., Fux, C.A., Vuichard-Gysin, D., Abbas, M., Marschall, J., Balmelli, C., Troillet, N., Harbarth, S., Schlegel, M., Widmer, A., Balmelli, C., Eisenring, M.C., Harbarth, S., Marschall, J., Pittet, D., Sax, H., Schlegel, M., Schweiger, A., Senn, L., Troillet, N., ... Swissnoso (2020). Risk of SARS-CoV2 transmission by aerosols, the rational use of masks, and protection of healthcare workers from COVID-19. Antimicrob. Resist. Infect. Control 9, 100. https://doi.org/10.1186/s13756-020-00763-0

Stadnytskyi, V., Bax, C.E., Bax, A., Anfinrud, P. (2020). The airborne lifetime of small speech droplets and their potential importance in SARS-CoV-2 transmission. PNAS 117, 11875-11877. https://doi.org/10.1073/pnas.2006874117

van Doremalen, N., Bushmaker, T., Morris, D.H., Holbrook, M.G., Gamble, A., Williamson, B.N., Tamin, A., Harcourt, J.L., Thornburg, N.J., Gerber, S.I., Lloyd-Smith, J.O., de Wit, E., Munster, V.J. (2020). Aerosol and surface stability of SARS-CoV-2 as compared with SARS-CoV-1. N. Engl. J. Med. 16, 1564-1567. https://doi.org/10.1056/NEJMc2004973

Watanabe, T., Bartrand, T.A., Weir, M.H., Omura, T., Haas, C.N. (2010). Development of a doseresponse model for SARS coronavirus. Risk Anal. 30, 1129-1138. https://doi.org/10.1111/j.15 39-6924.2010.01427.x

Wee, L.E.I., Sim, X.Y.J., Conceicao, E.P., Aung, M.K., Tan, K.Y., Ko, K.K.K., Wong, H.M., Wijaya, L., Tan, B.H., Venkatachalam, I., Ling, M.L. (2020). Containing COVID-19 outside the isolation ward: 
The impact of an infection control bundle on environmental contamination and transmission in a cohorted general ward. Am. J. Infect. Control 48, 1056-1061. https://doi.org/10.1016/j.a jic.2020.06.188

World Health Organization (WHO) (2020). Transmission of SARS-CoV-2: Implications for infection prevention precautions. World Health Organization. https://www.who.int/news-room/comm entaries/detail/transmission-of-sars-cov-2-implications-for-infection-prevention-precautions (accessed 03 January 2020)

Wu, S., Wang, Y., Jin, X., Tian, J., Liu, J., Mao, Y. (2020). Environmental contamination by SARSCoV-2 in a designated hospital for coronavirus disease 2019. Am. J. Infect. Control. 48, 910914. https://doi.org/10.1016/j.ajic.2020.05.003

Ye, G., Lin, H., Chen, S., Wang, S., Zeng, Z., Wang, W., Zhang, S., Rebmann, T., Li, Y., Pan, Z., Yang, Z., Wang, Y., Wang, F., Qian, Z., Wang, X. (2020). Environmental contamination of SARS-CoV-2 in healthcare premises. J. Infect. 81, e1-e5. https://doi.org/10.1016/j.jinf.2020.04.034 